\title{
DOSE DE EXPOSIÇÃO RADIOMÉTRICA E COMPOSIÇÃO DAS ROCHAS SEDIMENTARES E ÍGNEAS NA BACIA DO RIO CORUMBATAÍ (SP)
}

\author{
Fabiano Tomazini da Conceição ${ }^{1}$ e Daniel Marcos Bonotto ${ }^{2}$ \\ Recebido em 13 junho, 2005 / Aceito em 19 janeiro, 2006 \\ Received on June 13, 2005 / Accepted on January 19, 2006
}

\begin{abstract}
This work evaluated the activity concentration of radionuclides on sedimentary and igneous rocks at Corumbataí river basin, São Paulo State, and, consequently, the exposure rate. This basin possess a large sugar cane crops area, where occurs the application of phosphate fertilizers, and where is located the most important ceramic center of South America (Santa Gertrudes Ceramic Center). The chemical characterization of the samples indicated that $\mathrm{Ca}>\mathrm{Mg}>\mathrm{K}>\mathrm{Na}$, which is related to the mineralogy of each formation. The weighted mean exposure rate $\left(35 \mathrm{nGhh}^{-1}\right)$ to the studied formations represent just $64 \%$ of the world average due to terrestrial gamma radiation, occurring the highest exposure rate at the south-east portion of the area. The data obtained can be utilized in environmental studies involving the basin, including those related to the land use.
\end{abstract}

Keywords: Radioactivity, Gamma exposure rate, Watershed.

RESUMO. Este trabalho avaliou a atividade dos radionuclídeos em rochas sedimentares e ígneas da bacia do Rio Corumbataí, estado de São Paulo, e, conseqüentemente, a taxa de exposição. Esta bacia possui uma grande área com cultura de cana-de-açúcar, onde há intensa aplicação de fertilizantes fosfatados e também abriga 0 mais importante pólo cerâmico da América do Sul (Pólo Cerâmico de Santa Gertrudes). A caracterização química das amostras mostrou uma concentração de Ca $>$ Mg $>\mathrm{K}>\mathrm{Na}$, sendo essa relação devido à composição mineralógica de cada formação. A média ponderada da taxa de exposição ( $35 \mathrm{nG}$ Gh $\left.\mathrm{h}^{-1}\right)$ para as formações estudadas representa apenas $64 \%$ da média mundial devido à radiação gama terrestre, sendo que a porção sudeste da área exibe a mais alta taxa de exposição. Os resultados obtidos podem ser utilizados em estudos ambientais envolvendo a bacia do Rio Corumbataí, inclusive aqueles sobre o uso do solo.

Palavras-chave: Radioatividade, Dose de exposição gama, Bacia Hidrográfica.

\footnotetext{
1 Unidade Diferenciada Sorocaba/lperó (UDSI)/UNESP/Sorocaba/lperó. Av. Três de Março, 511, 18087-180 Alto da Boa Vista, Sorocaba, São Paulo, Brasil. Fone: (15) 3238-3413 - E-mail: ftomazini@sorocaba.unesp.br

2 Instituto de Geociências e Ciências Exatas (IGCE)/UNESP/Rio Claro. Av. 24-A, 1515, CP. 178, 13506-900 Bela Vista, Rio Claro, São Paulo, Brasil. Fone: (19) 35262825 -E-mail: dbonotto@rc.unesp.br
} 


\section{INTRODUÇ̃̃̃O}

Adubos minerais e inorgânicos (fertilizantes fosfatados) são muito utilizados na agricultura brasileira e mundial como fonte de macro e micro nutrientes para culturas onde o solo é empobrecido. Os fertilizantes fosfatados, de acordo com sua origem, podem conter vários elementos menores e traços, incluindo-se radionuclídeos ${ }^{238} \mathrm{U},{ }^{226} \mathrm{Ra}$, ${ }^{232} \mathrm{Th}$ e $\left.{ }^{40} \mathrm{~K}\right)$, metais pesados $(\mathrm{Cd}, \mathrm{Cr}$, $\mathrm{Cu}, \mathrm{Ni}, \mathrm{Pb}$ e Zn) e flúor (Menzel, 1968; Pfister et al., 1976; Camelo et al., 1997; Mirlean et al., 2001). A adição destes elementos a partir do uso de fertilizantes já foi descrita para solos (Malavolta, 1994; Rothbaum et al., 1979) e em drenagem de irrigação de terras fertilizadas (Spalding \& Sackett, 1972).

Ferreira et al. (1997) registraram anomalias radiométricas em solos desenvolvidos de rochas básicas (diabásios) em regiões intensamente cultivadas no município de Araras, Estado de São Paulo. Estes solos são conhecidos por apresentarem baixa concentração de radionuclídeos, sendo as anomalias atribuídas a impurezas em fertilizantes fosfatados utilizados há mais de 35 anos em plantações de cana-de-açúcar. Conceição \& Bonotto (2003) concluíram que aproximadamente $43 \%$ (no período chuvoso) da concentração de urânio dissolvido nas águas superficiais da bacia do Rio Corumbataí é de origem antropogênica ou seja, devido ao uso de fertilizantes fosfatados em culturas de cana-de-açúcar.

0 conhecimento da dose de exposição radiométrica das rochas da bacia do Rio Corumbataí é importante para a avaliação da contribuição da radioatividade natural devido aos radionuclídeos presentes, permitindo gerar parâmetros que subsidiem a realização de estudos ambientais na área, enfocando a aplicação de fertilizantes fosfatados. Essa bacia foi escolhida por compreender todas as unidades da Bacia Sedimentar do Paraná e por situar-se no Estado de São Paulo. Esse estado produz uma porção significativa do total da cana-de-açúcar brasileira, sendo também o principal cultivo ( $55 \%$ do uso e ocupação do solo) na bacia do Rio Corumbataí, de maneira que fertilizantes estão envolvidos nesta atividade (Conceição \& Bonotto, 2002).

Um outro aspecto importante relaciona-se ao fato de que na bacia do Rio Corumbataí localiza-se o importante Pólo Cerâmico de Santa Gertrudes (o maior pólo cerâmico das Américas), responsável pela produção de cerca de 20 milhões de $\mathrm{m}^{2}$ de revestimento cerâmico por mês (via seca) em 42 unidades produtoras concentradas em 3 municípios (Santa Gertrudes, Rio Claro e Cordeirópolis) (Christofoletti, 2003; Motta et al., 2004). Estas rochas, em especial as rochas argilosas da Formação Corumbataí, são a fonte de matéria-prima para estes revestimentos e, dependendo da dose de exposição radiométrica, estes revestimentos não podem ser exportados.

Assim, este trabalho descreve a avaliação a concentração de radionuclídeos $\left({ }^{238} \mathrm{U},{ }^{234} \mathrm{U},{ }^{226} \mathrm{Ra},{ }^{232} \mathrm{Th}\right.$ e ${ }^{40} \mathrm{~K}$ ) em rochas sedimentares e ígneas da bacia do Rio Corumbataí (SP), relacionando a sua distribuição aos processos sedimentares/magmáticos e de alteração das rochas sob as condições climáticas atuais. Os dados de concentração permitiram estimar a dose de exposiçã̃o radiométrica para toda a bacia e avaliar o potencial de toxicidade devido os radionuclídeos.

\section{CARACTERÍSTICAS GERAIS DA BACIA DO RIO CORUMBATAI}

A bacia do Rio Corumbataí possui uma área de aproximadamente $1.710 \mathrm{~km}^{2}$, situando-se na porção centro-leste do Estado de São Paulo entre os paralelos $22^{\circ} 05^{\prime}$ e $22^{\circ} 40^{\prime}$ de latitude sul e meridianos $47^{\circ} 55^{\prime}$ e $47^{\circ} 30^{\prime}$ a oeste de Greenwich (Fig. 1). A bacia do Rio Corumbataí situa-se na Depressão Periférica Paulista (Penteado, 1976) como faixa erosiva deprimida entre escarpas mais avançadas da zona de cuestas, que delimitam a borda oriental dos derrames basálticos, com desníveis da ordem de 200 a 300 metros, e o Planalto Cristalino. Em relação ao uso e ocupação de solo, além de plantações de cana-de-açúcar (55\%), verifica-se também pastagem (28\%), matas, cerrados ou florestas ( $6 \%$ ), reflorestamento (5\%), laranja (3\%) e outras culturas (3\%).

A área é drenada pelo Rio Corumbataí, sendo seus principais afluentes os rios Passa Cinco e das Cabeças e o Ribeirão Paraíso na margem direita, e o Ribeirão Claro e o Córrego da Assistência na margem esquerda. 0 clima da área é do tipo Aw (classificação de Köppen, 1948), ou seja, clima tropical chuvoso, com chuvas no verão e inverno seco. A temperatura média anual em quase todos os meses do ano é superior a $18^{\circ} \mathrm{C}$, ultrapassando no mês mais quente $22^{\circ} \mathrm{C}$. A média anual de chuva foi de $1505 \mathrm{~mm}$ nos últimos 21 anos (Conceição, 2000).

Do ponto de vista geológico, a bacia do Rio Corumbataí está inserida na Bacia Sedimentar do Paraná e diversas de suas unidades estratigráficas cobrem esta bacia (IPT, 1981) (Fig. 1): Subgrupo Itararé e Formação Tatuí do Grupo Tubarão, formações Irati e Corumbataí do Grupo Passa Dois, formações Pirambóia, Botucatu, Serra Geral e rochas básicas intrusivas do Grupo São Bento e diferentes tipos de coberturas Cenozóicas, como a Formação Rio Claro, depósitos recentes e terraços sedimentares. Entre os vários tipos de solos que ocorrem na bacia do Rio Corumbataí, os Argissolos e Latossolos cobrem aproximadamente 65\% da área dessa bacia (Köffler, 1993). 


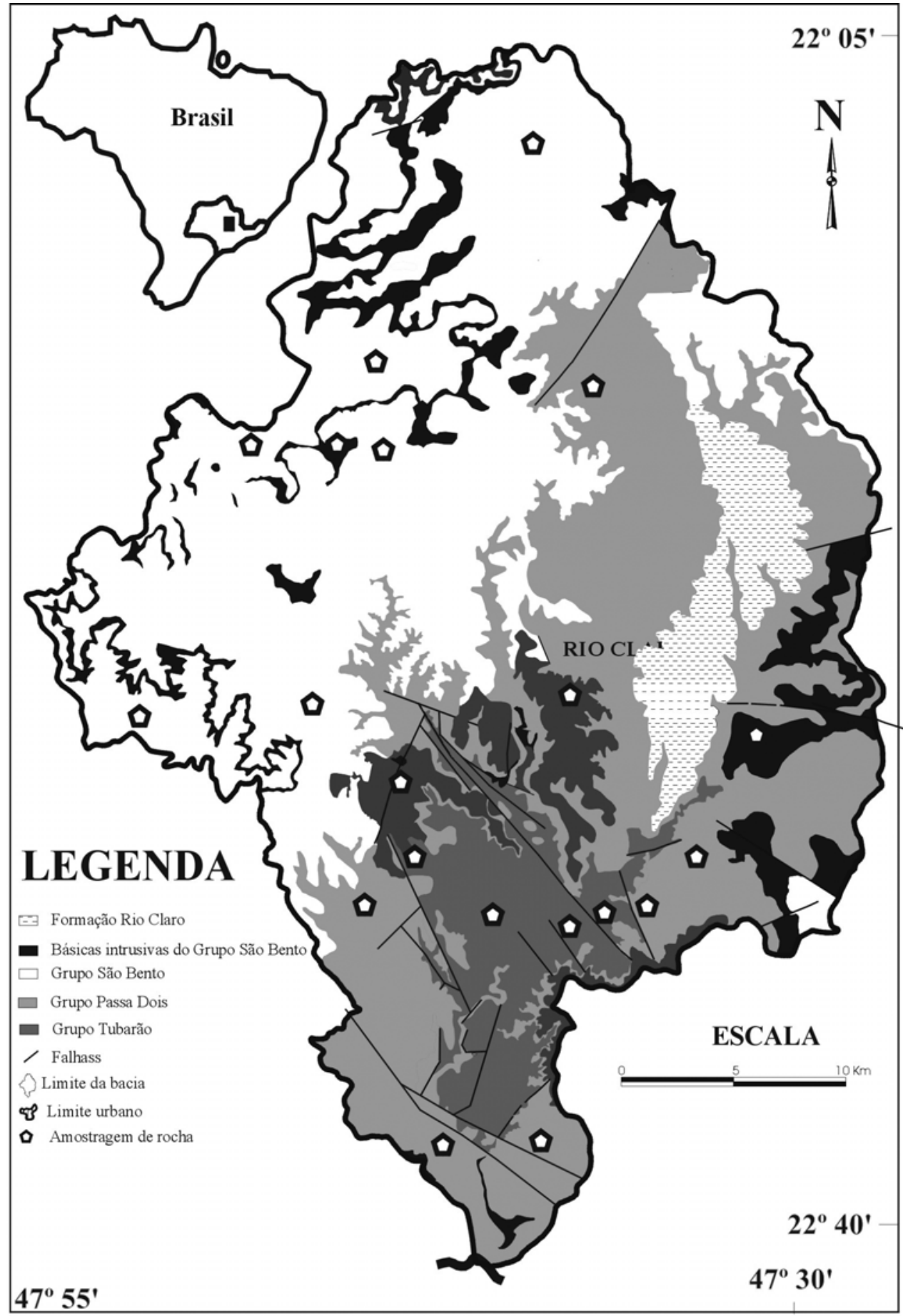

Figura 1 - Mapa geológico e localização dos pontos de coleta de rochas da bacia do Rio Corumbataí (SP).

\section{AMOSTRAGEM}

Vinte amostras de rocha foram coletadas por toda a área da bacia e selecionadas pela sua representatividade espacial, composição mineralógica e grau de alteração. Foi possível diferenciar as seguintes unidades estratigráficas: Subgrupo Itararé, Formação Tatuí, Formação Irati (Membro Taquaral e Membro Assistência), Formação Corumbataí, Formação Pirambóia, Formação Botucatu, Formação Rio Claro e Formação Serra Geral. 
As amostras do Subgrupo Itararé exibiram uma grande variação faciológica, sendo a primeira representada por diamictito de coloração avermelhada com grânulos de diferentes tamanhos e a segunda, representada por um arenito fino a médio, mal selecionado, de coloração branca-rósea, com laminação clino-ascendente (ripple drift). As amostras da Formação Tatuí constituíram-se de siltitos arenosos apresentando manchas esbranquiç̧adas de alteração e nódulos acebolados silicificados; próximo a este ponto observou-se um arenito bastante friável com $15 \mathrm{~cm}$ de espessura e ótima continuidade lateral (Fácies Ibicatu). As amostras da Formação Irati representaram o Membro Taquaral (siltito avermelhado e estratificado, contendo marcas onduladas) e o Membro Assistência (seqüência rítmica de folhelhos pretos pirobetuminosos e calcários dolomíticos, com um nítido espessamento das camadas de calcário em direção ao topo). As amostras na Formação Corumbataí foram representadas por siltitos arroxeados a amarelados (quando intemperizados), com fraturas concoidais, já empastilhados, maciços ou contendo leve laminação plano-paralela. As amostras coletadas na Formação Pirambóia consistiram de arenitos amareloavermelhados de granulação média a fina, silto-argilosos, mal selecionados, com estratificações cruzadas de grande porte. Arenitos com boa seleção, com grande estratificação cruzada planar tangencial representaram a Formação Botucatu. As amostras da Formação Serra Geral foram coletadas sobre corpos de diabásio (bastante fraturados), muitas vezes apresentando esfoliação esferoidal. Finalmente, as amostras da Formação Rio Claro consistiram em arenitos arcoseanos mal consolidados/classificados e arenitos conglomeráticos.

\section{TÉCNICAS ANALÍTICAS}

As amostras coletadas foram analisadas quanto aos principais elementos ( $\mathrm{Na}, \mathrm{Ca}, \mathrm{K}, \mathrm{Mg}, \mathrm{Al}, \mathrm{Si}, \mathrm{P} \mathrm{Ti}, \mathrm{Mn}$ e Fe) pela técnica de fluorescência de raios $X$ empregando o Espectrômetro da marca Phillips, modelo PW 2510, e caracterizadas mineralogicamente por difração de raios X (Siemens, modelo D5000), ambos equipamentos instalados no LABOGEO (Laboratório de Geoquímica) do Departamento de Petrologia e Metalogenia (DPM) da UNESP de Rio Claro (Gomes, 1984).

A concentração de urânio e a razão de atividade ${ }^{234} \mathrm{U} / 238 \mathrm{U}$ (RA) nas rochas foram determinadas por espectrometria alfa (Osmond \& Cowart, 1976; Ivanovich \& Harmon, 1992; Bonotto, 1996), onde $0^{232} \mathrm{U}$ foi o traçador utilizado. Aproximadamente $1 \mathrm{~g}$ de cada amostra foi moído até 200 mesh e submetida ao processo de dissolução com HF-HCl-HNO 3 em um sistema de digestão tipo
Parr 4745, de acordo com o descrito por Bonotto $(1986,1996)$, até completa dissolução. A solução foi evaporada até a secagem e o resíduo dissolvido com $\mathrm{HCl} 8 \mathrm{M}$. 0 urânio foi coprecipitado com $\mathrm{Fe}(\mathrm{OH})_{3}$, 0 ferro extraído com éter isopropílico e 0 urânio separado do tório e outros elementos em resina de troca aniônica. A alíquota contendo urânio foi transferida para célula de eletrodeposição e o urânio precipitado em disco de aço inoxidável após três horas (Bonotto, 1996). Um detector de barreira de superfície Si(Au) foi utilizado para a contagem da atividade alfa. A atividade dos isótopos de urânio foi calculada por diluição isotópica a partir da taxa de contagem nos picos de ${ }^{238} \mathrm{U},{ }^{234} \mathrm{U}$ e ${ }^{232} \mathrm{U}$ e a razão de atividade RA foi calculada a partir da taxa de contagem nos picos do ${ }^{238} \mathrm{U}$ e ${ }^{234} \mathrm{U}$.

A espectrometria gama foi utilizada para quantificar a atividade de ${ }^{226} \mathrm{Ra}$, ${ }^{232} \mathrm{Th}$ e ${ }^{40} \mathrm{~K}$ nas rochas. Um cristal de Nal(TI) foi calibrado para a leitura em atividade com padrões adquiridos do NBL (New Brunswick Laboratory - United State Departament of Energy) e com KCl (PA), de acordo com o procedimento descrito por Duarte (1997). As amostras foram moídas, acondicionadas em caixas de alumínio ( $62 \mathrm{~mm}$ de diâmetro e 23 mm de altura) e seladas para obter, em quatro semanas, equilíbrio radioativo entre ${ }^{2226} \mathrm{Ra}$ e seus descendentes de curta meia-vida. A atividade de ${ }^{226}$ Ra foi avaliada através da emissão de raios gama $(1,76 \mathrm{MeV})$ de seu filho ${ }^{214} \mathrm{Bi} ; 0^{232}$ Th foi determinado através da emissão gama do ${ }^{208} \mathrm{Tl}(2,62 \mathrm{MeV}) ; 0{ }^{40} \mathrm{~K}$ foi mensurado a partir do seu pico de energia gama correspondente a 1,46 MeV (Duarte, 1997).

Para a estimativa da dose de radiação gama devida aos radionuclídeos foi utilizado o $\mathrm{Ra}_{\mathrm{eq}}$, assumindo que $370 \mathrm{~Bq}$ de ${ }^{226} \mathrm{Ra} / \mathrm{kg}$, $259 \mathrm{~Bq}$ de ${ }^{232} \mathrm{Th} / \mathrm{kg}$ e $4.810 \mathrm{~Bq}$ de ${ }^{40} \mathrm{~K} / \mathrm{kg}$ produzem a mesma dose gama e é definido como (Beretka \& Mathew, 1985):

$$
\mathrm{Ra}_{\mathrm{eq}}=A_{\mathrm{Ra}}+1,43 A_{\mathrm{Th}}+0,077 A_{\mathrm{K}}
$$

onde: $A_{\mathrm{Ra}}, A_{\mathrm{Th}}$ e $A_{\mathrm{K}}$ são as atividades de ${ }^{226} \mathrm{Ra},{ }^{232} \mathrm{Th}$ e ${ }^{40} \mathrm{~K}$ em $\mathrm{Bq} / \mathrm{kg}$, respectivamente.

\section{RESULTADOS E DISCUSSÃO \\ Elementos principais e mineralogia}

A mineralogia e a concentração dos principais elementos nas amostras de rocha analisadas estão representadas na Tabela 1. A bacia do Rio Corumbataí (Fig. 1) é recoberta em 51\% por arenitos e conglomerados areníticos, 33\% por argilitos, $8 \%$ por siltitos, folhelhos betuminosos e calcários e 8\% por basaltos, diabásios e rochas intrusivas básicas associadas.

Os diamictitos do Subgrupo Itararé são constituídos de quartzo, albita, microclínio, caolinita e illita, enquanto que os arenitos possuem quartzo, caolinita, illita, microclínio e calcita. Os 
siltitos da Formação Tatuí são compostos por quartzo, caolinita, dolomita e illita. 0 Membro Taquaral (Formação Irati) é composto por rochas siltíiticas (quartzo, illita e caolinita) e o Membro Assistência da mesma formação é caracterizado por rochas calcárias dolomíticas (quartzo, dolomita e caolinita). A base da Formação Corumbatai é composta por quartzo, hematita, illita, caolinita, calcita, microclínio e albita, enquanto o topo dessa formação apresenta quartzo, illita, caolinita e hematita. Assim, a Formação Corumbataí, em sua base, possui uma maior concentração de $\mathrm{Ca}$, 0 que é evidenciado pela diferença mineralógica entre base e topo dessa formação. Os arenitos da Formação Pirambóia são compostos por quartzo e caolinita. A Formação Pirambóia difere da Botucatu pela presença de illita nesta última. Quartzo, magnetita, augita e labradorita são os constituintes minerais dos diabásios da Formação Serra Geral e das rochas intrusivas básicas. A Formação Rio Claro é composta por quartzo, caolinita, gibbsita e raramente por rutilo.

Conforme se verifica na Tabela 1, as rochas da bacia do Rio Corumbataí são empobrecidas em sódio relativamente aos metais alcalinos e alcalinos-terrosos analisados, pois, em sua maioria, são rochas sedimentares constituídas principalmente por quartzo, feldspato e argilo-minerais. Os maiores valores de sódio foram obtidos para as amostras de diabásio (labradorita). Em relação ao magnésio, conforme esperado, a maior concentração foi obtida para a amostra de calcário dolomítico do membro Assistência da Formação Irati, o que também se verificou para o cálcio. Uma amostra da Formação Corumbataí exibiu o valor mais elevado de potássio apesar de que as amostras do Subgrupo Itararé também apresentaram teores não muito diferentes. Os valores médios obtidos para esses quatro elementos mostram que $\mathrm{Ca}>\mathrm{Mg}>\mathrm{K}$ $>$ Na para os principais litotipos da bacia do Rio Corumbataí (Tabela 1).

Se a concentração dos elementos residuais (Fe, Al e Ti) é representada em um diagrama ternário (Fig. 2), quatro diferentes grupos são obtidos: Grupo A - arenitos e siltitos ricos em Al devido a presença de caolinita (amostras do Subgrupo Itararé e formações Tatuí, Irati, Pirambóia e Botucatu); Grupo B - argilitos com menor Al e maior Fe que os arenitos e siltitos (presença de hematita e caolinita em menor quantidade que 0 Grupo A); Grupo $\mathrm{C}$ - conglomerados areníticos (amostras da Formação Rio Claro) caracterizados pela presença de elementos insolúveis (Al, Fe and Ti) em proporções quase iguais (caolinita, goethita, gibbsita e rutilo); Grupo D - diabásios enriquecidos em Fe (valores maiores de ferro devido a presença de magnetita na Formação Serra Geral). Se a amostra de calcário dolomítico fosse inserida no diagrama da Fig. 2, ela pertenceria ao Grupo B, o que é incompatível com a mineralogia das rochas deste grupo que apresentam minerais portadores de Al, Fe e Ti.

Pedro \& Sieffermann (1979) consideram que 0 intemperismo deve-se basicamente à alteração de minerais primários, ou seja: minerais primários + solução de ataque $=$ minerais secundários + lixiviados. A degradação primária ou total destruição das estruturas dos minerais primários pode produzir fases secundárias, onde o processo é fortemente influenciado pela natureza dos minerais primários, clima, biosfera e pelo tempo (Martini \& Chesworth, 1992). Em relação aos processos intempéricos, a bacia do Rio Corumbataí está inserida em uma região onde o clima (pluviosidade de $1505 \mathrm{~mm} / \mathrm{ano}$ e temperatura de $22^{\circ} \mathrm{C}$ ) causa uma alteração química moderada, com predomínio do processo de monossialitização (geração de argilo-minerais, tipo caolinita caracterizada pela relação 1:1 de Si:Al). Esse processo ocorre pela hidrólise parcial da rocha mãe, com parte do Si permanecendo no perfil de alteração e $\mathrm{Na}, \mathrm{Ca}, \mathrm{K}$ e Mg sendo eliminados (Toledo et al., 2000). Assim, o Na é esperado ser lixiviado pela hidrólise da albita e labradorita, Ca pela dissolução da calcita e dolomita e pela hidrólise da labradorita e augita, Mg pela dissolução da dolomita e hidrólise da augita e K pela hidrólise do microclínio e caolinita (Fig. 3). A bacia do Rio Corumbataí não apresenta minerais que possuem $\mathrm{Cl}^{-}$(halita, silvita, etc.) ou $\mathrm{SO}_{4}^{2-}$ (gipso, etc.) nas suas fórmulas, sendo esperado pouca entrada desses elementos nas drenagens devido a interação água-rocha.

\section{Caracterização radiométrica}

A atividade dos radionuclídeos e a razão de atividade ${ }^{234} \mathrm{U} / 238 \mathrm{U}$ $\mathrm{e}^{226} \mathrm{Ra} /{ }^{238} \mathrm{U}$ nas rochas da bacia do Rio Corumbataí estão representadas na Tabela 2. A atividade de urânio nas rochas da bacia do Rio Corumbataí varia de $19 \mathrm{~Bq} / \mathrm{kg}$ para uma amostra de arenito da Formação Pirambóia até 398 Bq/kg para uma amostra de siltito da Formação Corumbataí. As amostras 7 e 9 fazem parte da porção superior da Formação Corumbataí e apresentam uma atividade maior de urânio quando comparada as amostras 8 e 10 da parte inferior desta formação, indicando que, apesar de todas as amostras terem sido depositadas em ambiente de planície de maré relacionada a um sistema deltáico (Gama Jr., 1979), as diferentes condições oxidantes e redutoras controlaram a distribuição do urânio durante os processos deposicionais.

Wedepohl (1969) e Gabelman (1977) consideraram que normalmente a concentração de urânio é maior em siltitos e argilitos que em arenitos, fato relacionado a granulometria dessas rochas e ao posicionamento diferencial do urânio nos seus minerais constituintes. A heterogeneidade geológica das rochas dessa 
DOSE DE EXPOSIÇÃO RADIOMÉTRICA E COMPOSIÇÃO DAS ROCHAS SEDIMENTARES E ÍGNEAS NA BACIA DO RIO CORUMBATAÍ (SP)

Tabela 1 - Mineralogia das amostras analisadas e principais elementos (\%) nas rochas da bacia do Rio Corumbataí (SP).

\begin{tabular}{|c|c|c|c|c|c|c|c|c|c|c|c|c|c|c|}
\hline Formação & Área (\%) & Mineralogia & Código & Descrição & $\mathrm{Na}_{2} \mathrm{O}$ & $\mathrm{MgO}$ & $\mathrm{K}_{2} \mathrm{O}$ & $\mathrm{CaO}$ & $\mathrm{Al}_{2} \mathrm{O}_{3}$ & $\mathrm{SiO}_{2}$ & $\mathrm{P}_{2} \mathrm{O}_{5}$ & $\mathrm{TiO}_{2}$ & $\mathrm{MnO}$ & $\mathrm{Fe}_{2} \mathrm{O}_{3}$ \\
\hline \multirow{2}{*}{ Itararé } & \multirow{2}{*}{5} & \multirow{2}{*}{$\begin{array}{c}\text { Quartzo, albita, } \\
\text { microclínio, caolinita }\end{array}$} & 1 & Diamictito & 0,07 & 2,32 & 4,59 & 0,28 & 14,88 & 69,54 & 0,09 & 1,04 & 0,07 & 5,32 \\
\hline & & & 2 & Arenito & 0,01 & 0,60 & 5,04 & 0,18 & 27,08 & 62,83 & 0,03 & 0,47 & 0,04 & 3,08 \\
\hline \multirow{2}{*}{ Tatuí } & \multirow{2}{*}{4,5} & \multirow{2}{*}{$\begin{array}{l}\text { Quartzo, caolinita, } \\
\text { dolomita, illita }\end{array}$} & 3 & Siltito & 0,01 & 0,90 & 0,83 & 0,07 & 15,33 & 76,17 & 0,03 & 0,33 & 0,02 & 1,38 \\
\hline & & & 4 & Siltito & 0,01 & 0,74 & 1,37 & 0,15 & 16,92 & 72,09 & 0,25 & 0,70 & 0,01 & 3,40 \\
\hline Irati (Taquaral) & 3,5 & Quartzo, illita, caolinita & 5 & Siltito & 0,01 & 1,25 & 1,49 & 0,14 & 13,90 & 76,52 & 0,05 & 0,65 & 0,01 & 3,87 \\
\hline Irati (Assistência) & 0,5 & Quartzo, dolomita & 6 & Calcário & 0,01 & 23,40 & 0,21 & 55,99 & 1,56 & 16,79 & 0,16 & 0,08 & 0,63 & 0,75 \\
\hline \multirow{4}{*}{ Corumbataí } & \multirow{4}{*}{30,5} & \multirow{4}{*}{$\begin{array}{l}\text { Quartzo, illita, } \\
\text { caolinita, microclínio, } \\
\text { albita, hematita, } \\
\text { calcita }\end{array}$} & 7 & Argilito & 0,01 & 1,73 & 1,56 & 0,17 & 17,09 & 67,28 & 0,18 & 0,77 & 0,07 & 4,69 \\
\hline & & & 8 & Argilito & 0,17 & 2,80 & 5,26 & 18,66 & 10,55 & 54,56 & 0,21 & 0,74 & 0,30 & 5,21 \\
\hline & & & 9 & Argilito & 0,30 & 2,24 & 3,80 & 3,23 & 12,44 & 67,60 & 1,12 & 0,81 & 0,10 & 6,97 \\
\hline & & & 10 & Argilito & 0,06 & 1,39 & 2,62 & 28,24 & 8,31 & 45,81 & 0,26 & 0,70 & 0,81 & 7,55 \\
\hline \multirow{4}{*}{ Pirambóia } & \multirow{4}{*}{31,5} & \multirow{4}{*}{ Quartzo, caolinita } & 11 & Arenito & 0,02 & 1,99 & 2,54 & 1,07 & 16,64 & 72,87 & 0,03 & 0,44 & 0,04 & 2,24 \\
\hline & & & 12 & Arenito & 0,01 & 0,26 & 0,57 & 0,08 & 10,56 & 85,65 & 0,05 & 0,41 & 0,08 & 2,23 \\
\hline & & & 13 & Arenito & 0,01 & 0,34 & 1,13 & 0,05 & 26,85 & 66,62 & 0,05 & 1,40 & 0,02 & 2,48 \\
\hline & & & 14 & Arenito & 0,03 & 2,58 & 2,97 & 0,53 & 17,33 & 71,21 & 0,10 & 0,55 & 0,06 & 2,19 \\
\hline \multirow{2}{*}{ Botucatu } & \multirow{2}{*}{6,5} & \multirow{2}{*}{ Quartzo, caolinita, illita } & 15 & Arenito & 0,01 & 0,49 & 3,82 & 0,34 & 9,06 & 82,57 & 0,09 & 0,57 & 0,03 & 2,25 \\
\hline & & & 16 & Arenito & 0,01 & 0,07 & 0,12 & 0,04 & 25,82 & 67,59 & 0,08 & 3,89 & 0,02 & 1,98 \\
\hline \multirow{2}{*}{ Serra Geral } & \multirow{2}{*}{8,5} & Quartzo, magnetita, & 17 & Diabásio & 0,32 & 2,31 & 1,93 & 8,50 & 14,04 & 49,37 & 0,75 & 4,66 & 0,20 & 16,61 \\
\hline & & augita, labradorita & 18 & Diabásio & 0,32 & 4,45 & 1,59 & 10,50 & 13,88 & 48,35 & 0,62 & 3,82 & 0,19 & 15,31 \\
\hline \multirow{2}{*}{ Rio Claro } & \multirow{2}{*}{9,5} & Quartzo, caolinita, & 19 & Conglomerado & 0,01 & 0,15 & 0,14 & 0,13 & 34,62 & 47,07 & 0,12 & 3,58 & 0,03 & 13,66 \\
\hline & & goethita, gibbsita, rutilo & 20 & Conglomerado & 0,01 & 0,10 & 0,12 & 0,06 & 30,02 & 53,83 & 0,11 & 3,30 & 0,03 & 12,04 \\
\hline Média Ponderada & 100 & & & & 0,07 & 2,51 & 2,08 & 6,42 & 16,85 & 62,71 & 0,20 & 1,45 & 0,14 & 5,66 \\
\hline
\end{tabular}

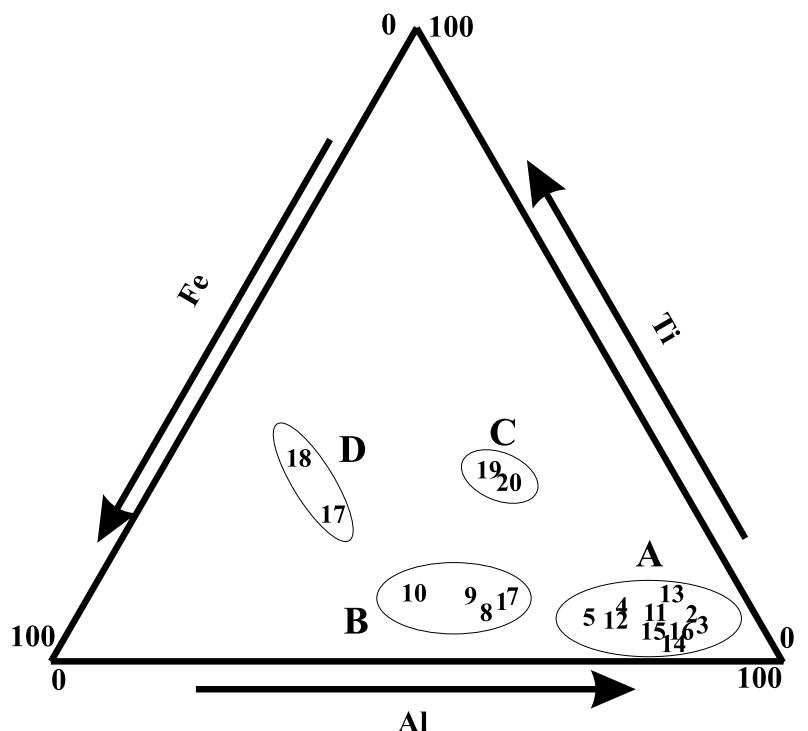

Figura 2 - Diagrama ternário utilizando os elementos residuais (Al, Fe e Ti) para as amostras de rochas coletadas na bacia do Rio Corumbataí. Grupo A: amostras do Subgrupo Itararé (arenito) e formações Tatuí, Pirambóia e Botucatu; Grupo B: amostras do Subgrupo Itararé (diamictito) e Formação Corumbataí (argilitos); Grupos C e D: amostras das formações Rio Claro e Serra Geral, respectivamente.

bacia implica em variação na concentração de urânio, pois, as mais argilosas tendem a possuir maior concentração de urânio, ao passo que as areníticas tendem a exibir menor concentração de urânio. As duas amostras do Subgrupo Itararé também confir- mam este fato, ou seja, diamictito e arenito exibem teor de urânio de $140 \mathrm{~Bq} / \mathrm{kg}$, e $49 \mathrm{~Bq} / \mathrm{kg}$, respectivamente. Ainda segundo esses autores, calcários deveriam apresentar atividade de urânio menor que $24,68 \mathrm{~Bq} / \mathrm{kg}$ (equivalente a $2 \mu \mathrm{g} / \mathrm{g}$ ), porém, isto não ocor- 


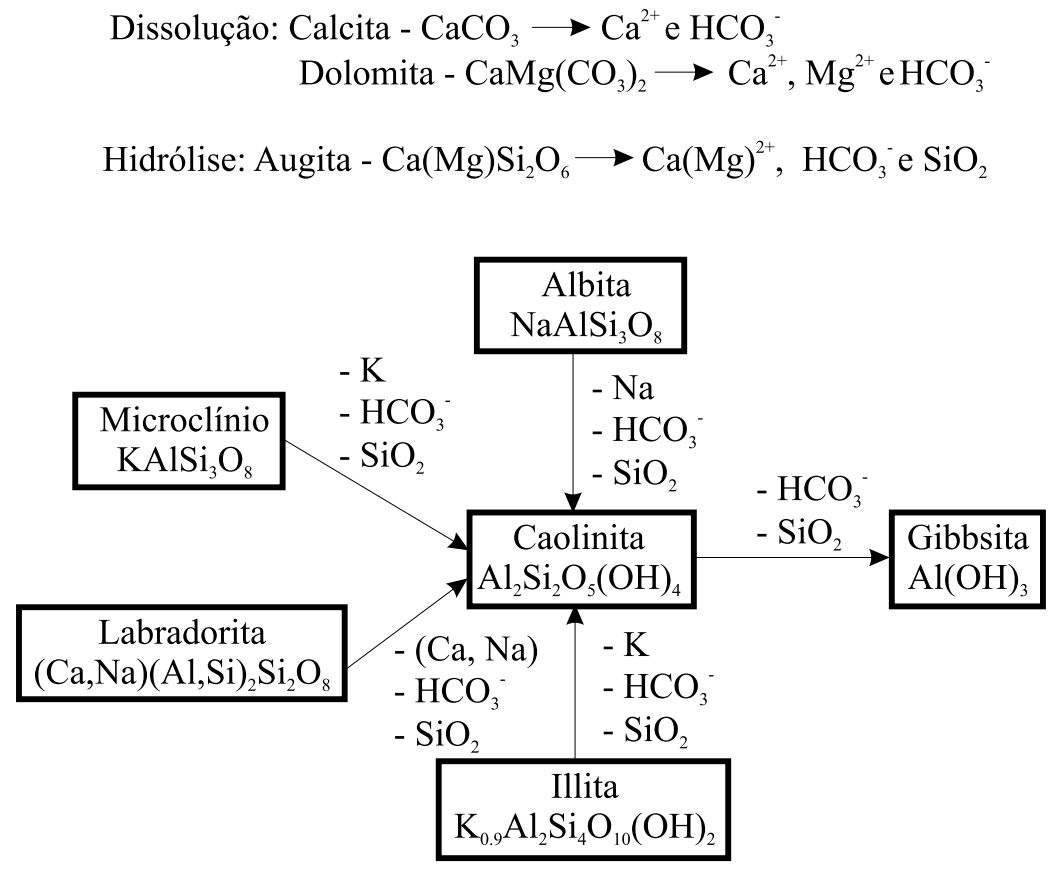

Figura 3 - Alternativas para a alteração mineral na bacia do Rio Corumbataí (SP).

reu com a amostra de calcário dolomítico do Membro Assistência que apresentou atividade de $191 \mathrm{~Bq} / \mathrm{kg}$. Essa alta concentração de urânio deve-se à composição desses calcários, ou seja, camadas de calcários dolomitizados e dolomitos (ambiente marinho raso) intercaladas por folhelhos pretos pirobetuminosos e piritosos (restrições da bacia), os quais são normalmente mais enriquecidos em urânio que outras rochas sedimentares (Krauskopf, 1972).

A razão de atividade ${ }^{234} \mathrm{U} /{ }^{238} \mathrm{U}$ nas amostras analisadas está entre 0,73 (Formação Tatuí) e 1,44 (Formação Corumbataí). Para quase todas as formações a razão de atividade correspondeu à unidade dentro da incerteza analítica do método empregado, constituindo a Formação Tatuí a única exceção (Tabela 2). A atividade de ${ }^{226} \mathrm{Ra}$ é menor que a de ${ }^{238} \mathrm{U}$ para todas as formações (Tabela 2), sugerindo lixiviação preferencial de ${ }^{226} \mathrm{Ra}$ em relação ao ${ }^{238} \mathrm{U}$. A maior atividade de ${ }^{232} \mathrm{Th}$ e ${ }^{40} \mathrm{~K}$ foi obtida para a Formação Corumbataí (Tabela 2). Testes estatísticos de correlação entre a atividade de ${ }^{40} \mathrm{~K}$ e concentração de $\mathrm{K}$ para todas as formações forneceram um coeficiente de correlação de 0,98 (Fig. 4), indicando compatibilidade entre os resultados obtidos pelas técnicas de espectrometria gama e fluorescência de raios $X$.

A Tabela 3 e Figura 5 apresentam a média ponderada da atividade dos radionuclídeos, $\mathrm{Ra}_{\mathrm{eq}}$ e dose de exposição radiométrica de todas as formações. A média da dose efetiva anual originada por fontes naturais corresponde a 2,4 mSv por ano e é equivalente a $R_{\text {eq }}=544 \mathrm{~Bq} / \mathrm{kg}$ (UNSCEAR, 1993). Todas as formações analisadas na bacia do Rio Corumbataí apresentam atividade de Ra $a_{\text {eq }}$ muito abaixo deste valor (Tabela 3), indicando que é baixo 0 nível de radioatividade dessas rochas. A dose de exposição é 0 efeito da radiação no ar acima de $1 \mathrm{~m}$ da área (UNSCEAR, 1993). 0 valor médio ponderado de $35 \mathrm{nGyh}^{-1}$ (Tabela 3) foi estimado a partir de fatores apropriados de conversão da taxa de dose de exposição gama (fator de conversão de taxa de exposição gama ou DRCF $=0,0414,0,623$ e $0,461 \mathrm{nGyh}{ }^{-1}$ por Bq/kg para ${ }^{40} \mathrm{~K},{ }^{232} \mathrm{Th}$ $\mathrm{e}^{226} \mathrm{Ra}$, respectivamente) adotados pela UNSCEAR (1993). Esse valor representa apenas 64\% da média mundial $\left(55 \mathrm{nGyh}^{-1}\right)$ de exposição devido à radiação gama terrestre (UNSCEAR, 1993). Dessa forma, a bacia do Rio Corumbataí pode ser considerada como uma área com baixa radioatividade natural, mesmo porque somente áreas com radiação gama externa maior que $230 \mathrm{nGyh}^{-1}$ são consideradas de alta exposição (UNSCEAR, 1993). Assim, a radiação externa adicional para a população devido às rochas sedimentares e ígneas da bacia do Rio Corumbataí é considerada mínima.

0 conhecimento da geologia da área e da dose de exposição média de cada formação permite gerar um mapa de isovalores da dose de exposição para as rochas sedimentares e ígneas na bacia do Rio Corumbataí. Para a obtenção destes mapas utilizou- 
DOSE DE EXPOSIÇÃO RADIOMÉTRICA E COMPOSIÇÃO DAS ROCHAS SEDIMENTARES E ÍGNEAS NA BACIA DO RIO CORUMBATAÍ (SP)

Tabela 2 - Radionuclídeos (Bq/kg) e razão de atividade ${ }^{234} \mathrm{U} / 238 \mathrm{U}$ e ${ }^{226} \mathrm{Ra} /{ }^{238} \mathrm{U}$ nas rochas da bacia do Rio Corumbataí (SP).

\begin{tabular}{|c|c|c|c|c|c|c|c|c|}
\hline Formação & Código & $238 \mathrm{U}$ & $234 U$ & ${ }^{226} \mathrm{Ra}$ & ${ }^{232} \mathrm{Th}$ & ${ }^{40} \mathrm{~K}$ & ${ }^{234} U / 238 U$ & ${ }^{226} \mathrm{Ra} /{ }^{238} \mathrm{U}$ \\
\hline \multirow{2}{*}{ Itararé } & 1 & 140 & 170 & 44 & 58 & 395 & 1,22 & 0,31 \\
\hline & 2 & 49 & 45 & 9 & 21 & 169 & 0,91 & 0,18 \\
\hline \multirow{2}{*}{ Tatuí } & 3 & 138 & 112 & 34 & 16 & 143 & 0,81 & 0,25 \\
\hline & 4 & 181 & 132 & 63 & 25 & 113 & 0,73 & 0,35 \\
\hline Irati (Taquaral) & 5 & 85 & 102 & 21 & 38 & 169 & 1,20 & 0,25 \\
\hline Irati (Assistência) & 6 & 191 & 210 & 51 & $<4$ & $<5$ & 1,10 & 0,27 \\
\hline \multirow{4}{*}{ Corumbataí } & 7 & 398 & 573 & 93 & 122 & 369 & 1,44 & 0,24 \\
\hline & 8 & 75 & 67 & 7 & 23 & 395 & 0,90 & 0,10 \\
\hline & 9 & 244 & 288 & 63 & 51 & 339 & 1,18 & 0,26 \\
\hline & 10 & 87 & 83 & 8 & 25 & 256 & 0,95 & 0,10 \\
\hline \multirow{4}{*}{ Pirambóia } & 11 & 70 & 80 & 20 & 16 & 199 & 1,14 & 0,28 \\
\hline & 12 & 19 & 18 & 6 & 5 & 56 & 0,94 & 0,31 \\
\hline & 13 & 76 & 80 & 22 & 15 & 113 & 1,05 & 0,29 \\
\hline & 14 & 34 & 36 & 10 & 9 & 169 & 1,05 & 0,29 \\
\hline \multirow{2}{*}{ Botucatu } & 15 & 23 & 28 & 17 & 5 & 113 & 1,22 & 0,40 \\
\hline & 16 & 43 & 46 & 18 & 10 & 226 & 1,07 & 0,42 \\
\hline \multirow{2}{*}{ Serra Geral } & 17 & 47 & 53 & 6 & 36 & 169 & 1,12 & 0,13 \\
\hline & 18 & 35 & 38 & 5 & 22 & 143 & 1,10 & 0,14 \\
\hline Rio Claro & 19 & 55 & 62 & 8 & 12 & $<5$ & 1,13 & 0,15 \\
\hline
\end{tabular}

Incerteza analítica $\pm 10 \%$ correspondente a um desvio padrão de $1 \sigma$.

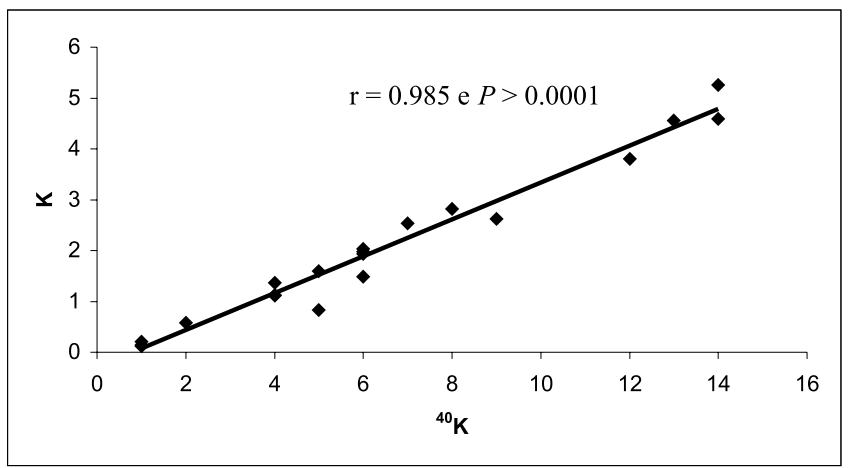

Figura 4 - Correlação entre ${ }^{40} \mathrm{~K}(\mathrm{~Bq} / \mathrm{kg})$ e K(\%) para as rochas da bacia do Rio Corumbataí (SP).

se a teoria das variáveis regionalizadas (Matheron, 1962), que vem se constituindo numa análise de fundamental importância para 0 estudo do comportamento espacial de fenômenos com uma continuidade geográfica. Inicialmente, seu enfoque foi voltado para problemas de mineração, mas, posteriormente, sua aplicação se estendeu à geologia ambiental, geologia de engenha- ria, hidrogeologia, etc (David, 1977 e Clark, 1979). 0 programa utilizado para confecção deste mapa foi o SURF para Windows. Para a estimação de valores, utilizou-se o processo de krigagem, que proporciona um estimador linear e não tendencioso, sendo mínima a variância da estimação (Landim, 1998). A Figura 6 ilustra a dose de exposição radiométrica obtida para as rochas sedi- 

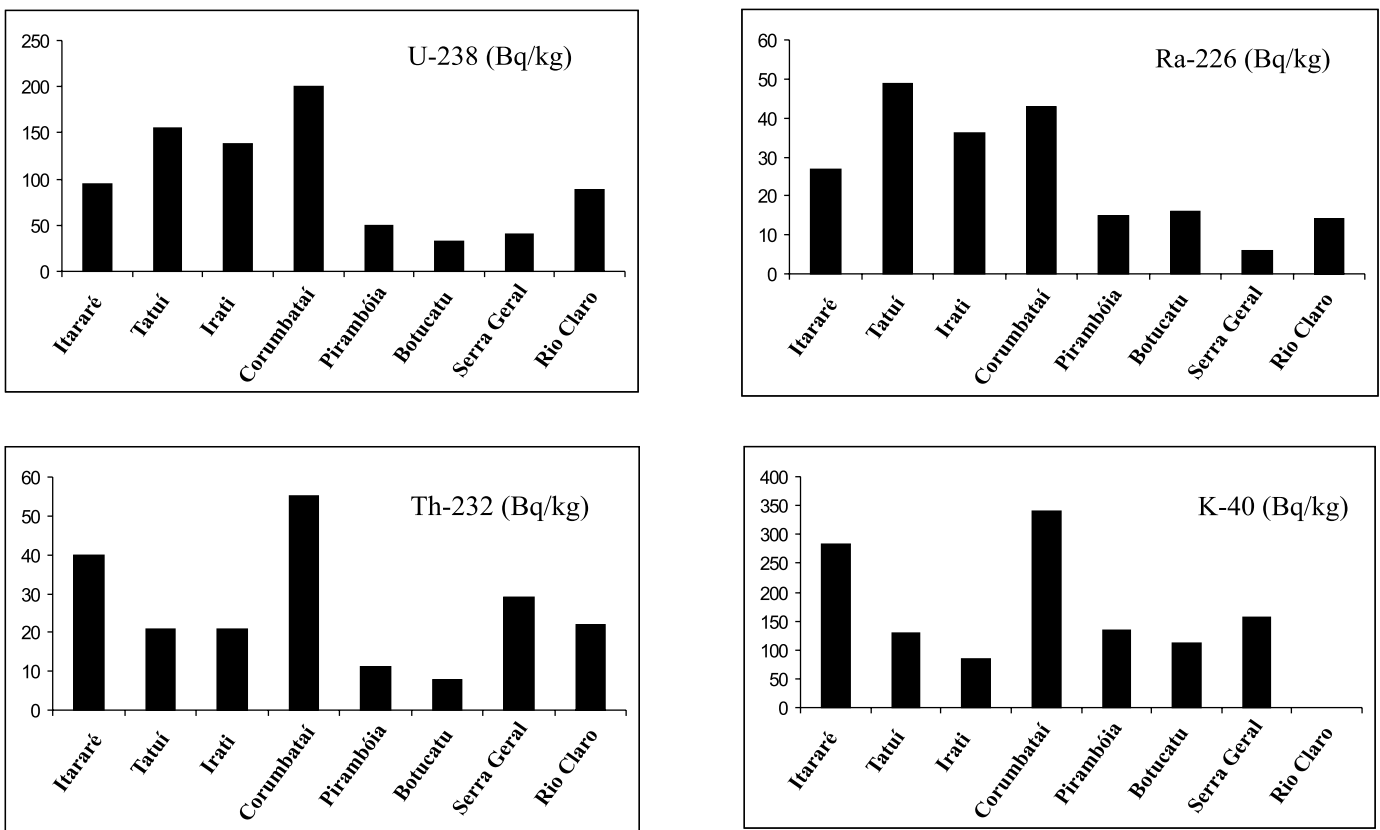

Figura 5 - Média ponderada para os radionuclídeos analisados nas formações estudadas da bacia do Rio Corumbataí (SP).

Tabela 3 - Atividade dos radionuclídeos, Raeq, taxa de exposição e razão de atividade ${ }^{234} \mathrm{U} / 238 \mathrm{U}$ e ${ }^{226} \mathrm{Ra} /{ }^{238} \mathrm{U}$ nas rochas da bacia do Rio Corumbataí (SP).

\begin{tabular}{|c|c|c|c|c|c|c|c|}
\hline Formação & $\begin{array}{c}\% \text { de } \\
\text { área }\end{array}$ & $\begin{array}{c}238 \mathrm{U} \\
(\mathrm{Bq} / \mathrm{kg})\end{array}$ & $\begin{array}{c}{ }^{226} \mathrm{Ra} \\
(\mathrm{Bq} / \mathrm{kg})\end{array}$ & $\begin{array}{c}{ }^{232} \mathrm{Th} \\
(\mathrm{Bq} / \mathrm{kg})\end{array}$ & $\begin{array}{c}40 \mathrm{~K} \\
(\mathrm{~Bq} / \mathrm{kg})\end{array}$ & $\begin{array}{c}\mathrm{Ra}_{\text {eq }} \\
(\mathrm{Bq} / \mathrm{kg})\end{array}$ & $\begin{array}{c}\mathrm{TE}^{1} \\
\left(\mathrm{nG}^{-1}\right)\end{array}$ \\
\hline Itararé & 5 & 95 & 27 & 40 & 282 & 105 & 48 \\
\hline Tatuí & 4,5 & 156 & 49 & 21 & 128 & 89 & 40 \\
\hline Irati & 4,0 & 138 & 36 & 21 & 85 & 73 & 33 \\
\hline Corumbataí & 30,5 & 201 & 43 & 55 & 340 & 148 & 60 \\
\hline Pirambóia & 31,5 & 50 & 15 & 11 & 134 & 41 & 19 \\
\hline Botucatu & 6,5 & 33 & 18 & 8 & 170 & 43 & 20 \\
\hline Serra Geral & 8,5 & 41 & 6 & 29 & 156 & 59 & 27 \\
\hline Rio Claro & 9,5 & 89 & 14 & 22 & $<5$ & 44 & 20 \\
\hline Média Ponderada & & $\mathbf{1 0 9}$ & $\mathbf{2 6}$ & $\mathbf{2 9}$ & $\mathbf{1 9 5}$ & $\mathbf{8 2}$ & $\mathbf{3 5}$ \\
\hline
\end{tabular}

${ }^{1}$ Taxa de exposição estimada pelo uso de DRCF (fator de conversão de taxa de exposição gama) = 0,0414, 0,623 e $0,461 \mathrm{nGyh}^{-1}$ por Bq/kg de ${ }^{40} \mathrm{~K},{ }^{232}$ Th e ${ }^{226} \mathrm{Ra}$, respectivamente (UNSCEAR, 1993).

mentares e ígneas da bacia do Rio Corumbataí. Como pode ser observado, o sudeste da bacia apresenta maior taxa de exposição, pelo fato de se encontrar rochas argilosas da Formação Corumbataí e siltosas da Formação Itararé, Tatuí e Irati. A cidade de Rio Claro situa-se nesta região, de maneira que seus habitantes estão sujeitos a dose maior de radiação que outros municípios da bacia do Rio Corumbataí. 0 restante da área exibe menor taxa de exposição relacionada com arenitos (Formação Pirambóia e Botucatu) e diabásios (Formação Serra Geral).

\section{CONSIDERAÇÕES FINAIS}

Esse trabalho permitiu avaliar a atividade de radionuclídeos em rochas sedimentares e ínneas, possibilitando a geração de um 

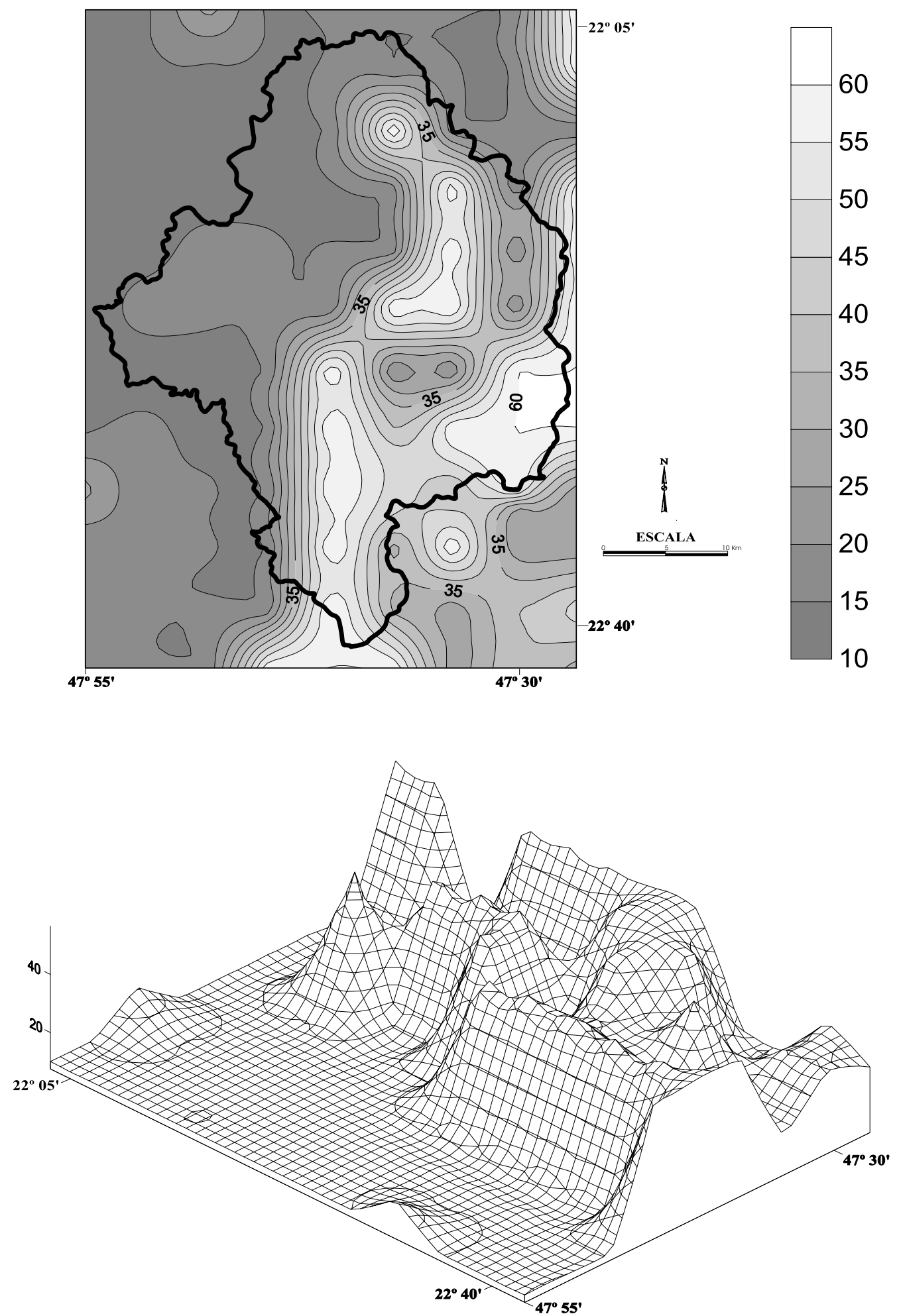

Figura 6 - Mapa de dose de exposição gama (nGyh ${ }^{-1}$ ) devido às rochas da bacia do Rio Corumbataí (SP). 
mapa de dose de exposição radiométrica na bacia do Rio Corumbatá (SP). A caracterização química destas amostras mostrou uma concentração de $\mathrm{Ca}>\mathrm{Mg}>\mathrm{K}>\mathrm{Na}$, sendo essa relação devido à composição mineralógica de cada formação. A atividade de ${ }^{238} \mathrm{U}$ está dentro da variação mundial para estas rochas, com os siltitos e argilitos apresentando maior atividade de ${ }^{238} \mathrm{U}$ que os arenitos, o que está relacionado à mineralogia e tamanho dos grãos. A taxa de exposição $\left(35 n \mathrm{nyh}^{-1}\right.$ ) para essas formações representa apenas $64 \%$ da média mundial devido a radiação gama terrestre, sendo a porção sudeste da área a que apresenta a mais alta taxa de exposição. Assim, esses resultados permitem avaliar uma baixa concentração natural de radionuclídeos nas rochas sedimentares e ígneas da bacia do Rio Corumbataí, gerando os parâmetros necessários para futuras comparações que envolvam problemas ambientais devido à aplicação de fertilizantes fosfatados (aumento de metais pesados e radionuclídeos em solos) e, principalmente, indicando que o uso destas rochas como matériaprima pode gerar revestimentos cerâmicos com baixa taxa de exposiç̧ão, fato importante para a exportação destes produtos.

\section{AGRADECIMENTOS}

Os autores agradecem à FAPESP (Processos no 98/02217-5 e 00/03136-0) pelo apoio financeiro durante a realização desta pesquisa.

\section{REFERÊNCIAS}

BERETKA J \& MATHEW PJ. 1985. Natural radioactivity of Australian building materials waste and by-products. Health Physics, 48: 87-95.

BONOTTO DM. 1986. Aplicações hidrogeoquímicas dos isótopos naturais das séries do $U(4 n+2)$ e $T h(4 n)$ no Morro do Ferro, Poços de Caldas (MG). Tese de doutorado, IAG - USP.

BONOTTO DM. 1996. Comportamento hidrogeoquímico do ${ }^{222} \mathrm{Rn}$ e isótopos de urânio ${ }^{238} \mathrm{Ue}^{234} \mathrm{U}$ sob condições controladas de laboratório e em sistemas naturais. Tese de Livre Docência, IGCE - UNESP.

CAMELO LGL, MIGUEZ SR \& MARBAN L. 1997. Heavy metals inputs in phosphate fertilizers used in Argentina. The Science of Total Environment, 204: 245-250.

CHRISTOFOLETTI SR. 2003. Um modelo de classificação geológicageotécnica das argilas da Formação Corumbatái utilizada nas indústrias de revestimentos cerâmicos. Tese de Doutorado, IGCE, UNESP, Rio Claro, $307 \mathrm{p}$.

CLARK I. 1979. Practical geostatistics. London, Applied Science Publishers. $129 \mathrm{p}$.

CONCEIÇÃO FT. 2000. 0 método do desequilíbrio isotópico do urânio aplicado no estudo do intemperismo na bacia do Rio Corumbataí (SP). Dissertação de Mestrado, IGCE, UNESP, Rio Claro, 142p.

CONCEIÇÃO FT \& BONOTTO DM. 2000. Anthropogenic influences on the uranium concentration in waters of the Corumbatá river basin (SP), Brazil. Revista Brasileira de Geociências, 30: 551-553.

CONCEIÇÃO FT \& BONOTTO DM. 2002. Relações hidroquímicas aplicadas na avaliação da qualidade da água e diagnóstico ambiental na bacia do Rio Corumbataí (SP). Geochimica Brasiliensis, 16(1): 1-21.

CONCEIÇÃO FT \& BONOTTO DM. 2003. Use of U-isotopes disequilibrium to evaluated the weathering rates and fertilizer-derived uranium at São Paulo State, Brazil. Environmental Geology, 44(4): 408-418.

DAVID M. 1977. Geostatistical ore reserve estimation. Amsterdam, Elsevier. $364 \mathrm{p}$.

DNPM. DEPARTAMENTO NACIONAL DE PRODUÇÃO MINERAL. 2000. Mineral Summary. DNPM. $116 \mathrm{p}$.

DNPM. DEPARTAMENTO NACIONAL DE PRODUÇ̃̃O MINERAL. 2001. Sumário Mineral. DNPM. 121 p.

DUARTE CR. 1997. Relações Radiométricas e isotópicas na área do Projeto Rio Preto (GO). Dissertação de Mestrado, IGCE - UNESP, 114 p.

FERREIRA FJF, SOUZA JL, ROCHA HO \& MANTOVANI LE. 1997. Airborne gamma-ray spectrometry and remote sensing to map uranium accumulation in soils from long-continued application of fertilizers in Araras region, Brazil. 12th International Conference Applied Geologic Remote Sensing, I: 323-330.

GABELMAN J. 1977. Migration of $U$ and The exploration significance. Study in geology N. 3. AAPG. $168 \mathrm{p}$.

GAMA Jr. EG. 1979. A sedimentação do Grupo Passa Dois (exclusive Formação Irati): um modelo geomórfico. Revista Brasileira de Geociências, 9(1): 1-16.

GOMES CB. 1984. Técnicas analíticas instrumentais aplicadas à Geologia. Edgard Blücher, São Paulo. 218 p.

IPT. Instituto de Pesquisa Tecnológica do Estado de São Paulo. 1981. Mapa Geológico do Estado de São Paulo. Monografias, São Paulo.

IVANOVICH M \& HARMON RS. 1992. Uranium Series Disequilibrium: Applications to Environmental Problems, $2^{\text {nd }}$ edition. Oxford Univ. Press, Oxford. $571 \mathrm{p}$.

KÖFFLER NF. 1993. Diagnósticos do uso agrícola das terras da Bacia do Rio Corumbataí, SP. Report, IGCE, UNESP. 102 p.

KÖPPEN W. 1948. Climatologia. México: Fondo de Cultura Econômica. $478 \mathrm{p}$.

KRAUSKOPF KB. 1972. Introdução à geoquímica. Editora USP. v.2, $311 \mathrm{p}$.

LANDIM PMB. 1998. Análise Estatística de Dados Geológicos. Ed. UNESP. $253 p$. 
MALAVOLTA E. 1994. Fertilizantes e seu impacto ambiental. São Paulo: Produquímica. $153 \mathrm{p}$.

MARTINI IP \& CHESWORTH W. 1992. Weathering, soils and paleosols. Elsevier Sciences Publications, Amsterdam. 618 p.

MATHERON G. 1962. Traité de geoestatistique appliquée. Paris, Technip $333 \mathrm{p}$.

MENZEL RG. 1968. Uranium, radium and thorium content in phosphate rocks and their possible radiation hazard. J. Agr. Food Chem., 16: 231284.

MIRLEAN N, ROISENBERG A, CRUZ RD, CASARTELLI R \& DOMINGUES MRG. 2001. Avaliação do flúor migrável das matérias primas e dos fertilizantes fosfatados utilizados no Rio Grande do Sul. In: Congresso Brasileiro de Geoquímica, VIII \& Simpósio de Geoquímica dos Países do Mercosul, I. Curitiba. CD-ROM com resumos expandidos.

MOTTA JFM, CHRISTOFOLETTI SR, GARCEZ LL, FLORÊNCIO RVS, BOSCHI AO, MORENO MMT, CUCHIERATO G \& ZANARDO A. 2004. Características do Pólo de Revestimentos Cerâmicos de Santa Gertrudes SP, com ênfase na produção de argila. Cerâmica Industrial, 9(1): 1-6.

OSMOND JK \& COWART JB. 1976. The theory and uses of natural uranium isotopic variations in hydrology. At. Energy Rev., 14: 621-679.

PEDRO G \& SIEFFERMANN G. 1979. Weathering of rocks and formation of soils. In: SIEGEL FR (Ed.). Review in Modern Problems of Geochemistry. UNESCO, pp. 39-55.

PENTEADO MM. 1976. Geomorfologia do setor centro-ocidental da Depressão Periférica Paulista. Série teses e monografias, 22. IGEOG/USP. $86 \mathrm{p}$.

PFISTER RJ, PHILIPP G \& PAULY H. 1976. Population dose from natural radionuclides in phosphate fertilizers. Radiation and Environmental
Biophysics, 13: 247-261.

ROTHBAUM HP, MCGAVESTON DA, WALL T, JOHNSTON AE \& MATTINGLY GEG. 1979. Uranium accumulation in soils from long-continued applications of superphosphate. European Journal of Soil Science, 30: 147-153.

SAUERBECK D. 1992. Conditions controlling the bioavailability of trace elements and heavy metals derived from phosphate fertilizers in soils. Proc. IMPHOS. Conf. On Phosphorous, Life and Environment, Casablanca, 419-448.

SCHNEIDER RF, MUHLMANN HE, MEDEIROS RA, DAEMON RF \& NOGUEIRA AA. 1974. Revisão Estratigráfica da Bacia do Paraná. In: Congresso Brasileiro de Geologia, 28; Porto Alegre. Anais... Porto Alegre: SBG, 1974, 1: 41-65.

SPALDING RF \& SACKETT WM. 1972. Uranium runoff from the Gulf of Mexico distributive province: anomalous concentrations. Science, 175: 629-631.

STURARO JR \& LANDIM PMB. 1988. Estudo do nível piezométrico por análise geoestatística. Geociências, 7: 201-210.

TOLEDO MCM, OLIVEIRA SMB \& MELFI A. 2000. Intemperismo e formação do solo. In: TEIXEIRA W, TOLEDO MCM, FAIRCHILD TR \& TAIOLI F (Eds.). Decifrando a Terra. Oficina de textos, São Paulo, 139166.

UNSCEAR. 1993. Sources and effects of ionizing radiation. United Nations Scientific Committee on the Effects of Atomic Radiation. United Nations, New York. 17 p.

WEDEPOHL KH. 1969. Handbook of Geochemistry. New York. 442 p.

\section{NOTAS SOBRE OS AUTORES}

Fabiano Tomazini da Conceição é graduado em Geologia, com Mestrado em Geociências e Doutorado em Geologia Regional no Instituto de Geociências e Ciências Exatas da UNESP de Rio Claro. Neste período, efetuou estudos, utilizando traçadores naturais (incluindo-se radioelementos), sobre a interação rocha-água/solo e as interferências provocadas pela ação antrópica neste processo. Participa de dois grupos de pesquisa: "Hidroquímica e Radioatividade na Geosfera" e "Grupo de Estudos Ambientais". É Professor Assistente Doutor pela Unidade Diferenciada Sorocaba/Iperó - UDSI - da UNESP de Sorocaba-SP, onde leciona Geologia Geral e Ambiental e outras disciplinas para graduandos em Engenharia Ambiental.

Daniel Marcos Bonotto é graduado em Física, com Mestrado e Doutorado em Geofísica no Instituto Astronômico e Geofísico da Universidade de São Paulo. Tem realizado investigações enfocando a presença de radioelementos naturais em diferentes contextos geológicos, as quais contribuem para o desenvolvimento das atividades do Grupo de Pesquisa em "Hidroquímica e Radioatividade na Geosfera", do qual é coordenador. É Professor Adjunto pelo Instituto de Geociências e Ciências Exatas IGCE-UNESP de Rio Claro-SP, onde leciona Geoquímica e outras disciplinas para graduandos em Geologia e pós-graduandos em Geociências e Geologia Regional. 